\title{
Application of WRF Model for Vehicular Pollution Modelling Using AERMOD
}

\author{
Awkash Kumar1*, Anil Kumar Dikshit ${ }^{1}$, Sadaf Fatima², Rashmi S. Patil1 \\ ${ }^{1}$ Centre for Environmental Science and Engineering, Indian Institute of Technology, Mumbai, India \\ ${ }^{2}$ School of Environment and Sustainable Development, Central University of Gujarat, Gandhinagar, India \\ Email: ${ }^{*}$ awkash.narayan@gmail.com
}

Received 12 February 2015; accepted 6 March 2015; published 10 March 2015

Copyright (C) 2015 by authors and Scientific Research Publishing Inc.

This work is licensed under the Creative Commons Attribution International License (CC BY).

http://creativecommons.org/licenses/by/4.0/

(c) (i) Open Access

\begin{abstract}
Vehicular pollution is becoming significant in urban areas because of increasing population. This is at ground level, so it gives high population exposure. In this study, Chembur, which is the most polluted area in Mumbai city due to industrial and vehicular sources, is selected for vehicular pollution modeling using AMS/EPA Regulatory Model (AERMOD). Meteorological parameters, land use surface characteristics and source emission data are collected as required by AERMOD. The results of modelling depend upon reliability of input data and meteorological data has a vital role in the performance of the model. Generally, temporally and spatially interpolated meteorological data is used in modeling. This is generally collected from nearby meteorological station but this causes inaccuracy of the results. In this paper, the Weather Research and Forecasting (WRF) model has been used to generate onsite data on nine meteorological parameters. The modeling of six roads of Chembur has been performed using above meteorological data. This approach gives good results of traffic modeling. The results of AERMOD are compared with observed air quality which has contribution from all sources in the region and relative contribution of vehicular sources identified.
\end{abstract}

\section{Keywords}

Vehicular Pollution Modeling, AERMOD, WRF

\section{Introduction}

Most of the metropolitan cities of the world have heavy transportation load to complete needs of the people of the city. This load is increasing with respect to time as the population is increasing. This increasing transportation load is making it difficult to manage the health and safety of societies. There are many kinds of sources of

\footnotetext{
*Corresponding author.
}

How to cite this paper: Kumar, A., Dikshit, A.K., Fatima, S. and Patil, R.S. (2015) Application of WRF Model for Vehicular Pollution Modelling Using AERMOD. Atmospheric and Climate Sciences, 5, 57-62. 
emission like industrial, vehicular and domestic sector in the megacities but vehicular sources are at ground level source and so have severe effect on human health and environment [1]-[9]. It is important to make better and healthy environment, which requires study of vehicular pollution. The Chembur region of the Mumbai city has been selected for study of vehicular pollution. There are many ways to model vehicular pollution. The most widely used ones are Gaussian based, viz. CALINE3 model, EPA's HIWAY-2 model and GM model [10]-[12]. The modified HIWAY model (called HIWAY-2) and the GM model are applicable to a situation where the upwind segment of the road (measured from the perpendicular line drawn from the receptor) is at least three times the distance between the receptor and the road. Hence, the GM model overpredicts the concentration by a considerable amount if the above constraint is not satisfied [13]. The above constraint can be handled by using the HIWAY-2 model but its performance is not as accurate as that of the GM model [14]. Moreover, the HIWAY-2 and CALINE3 models require rigorous computer calculations to estimate the value of integration. A model was developed by Csanady for a finite line source which is applicable for any orientation of wind with roadways [15]. All these models require meteorological data, surface characteristics and emission data of vehicles. In the present study, a new approach to vehicular pollution modelling has been attempted and compared with observed data.

\section{Study Area}

Chembur is a highly polluted region by industries as well as vehicles. Its latitude and longitude are $19.05^{\circ} \mathrm{N}$ and $72.89^{\circ} \mathrm{E}$ respectively. The study area is 6.5 kilometres east-to-west and 8.45 kilometres north-to-south as shown in Figure 1. It contains heavy duty vehicles on Port Trust Road, Mahul Road and Ramakrishna Chemburkar Marg. Due to continuous movement of heavy vehicles, road conditions are getting worse. It has four major industries such as two refineries (BPCL and HPCL), a fertilizer (RCFL) and a power plant (TPCL). WRF model

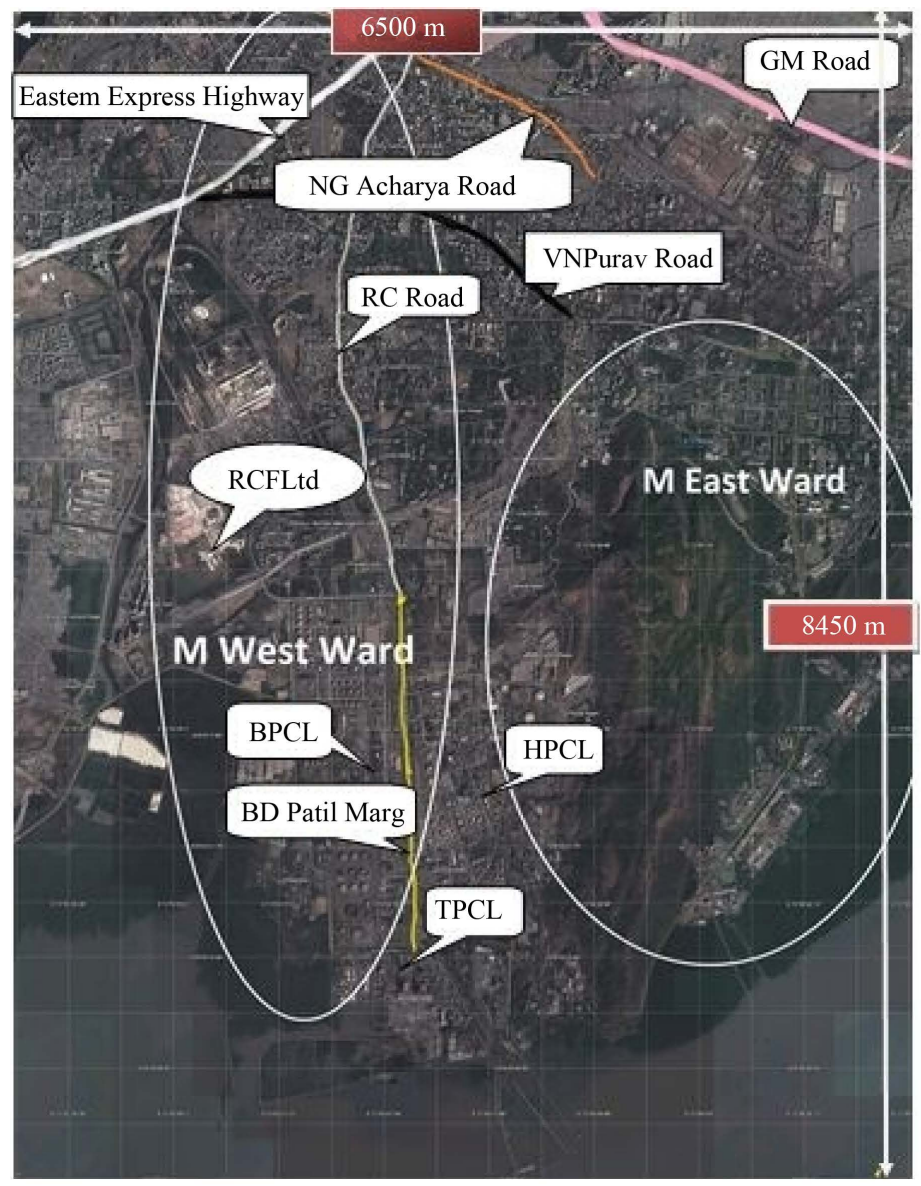

Figure 1. Study area Chembur. 
was used to derive meteorology for input in air quality model. Nine parameters on meteorology were generated using WRF model and fed in AERMET which is preprocessor of AERMOD.

\section{Methodology}

Air quality model requires two kinds of input data viz. emission data and meteorological data. Emission inventory was prepared using actual number of vehicles, respective emission factors and vehicle kilometer travelled (VKT). Vehicle counting was done for six roads of Chembur and emission inventory data was assembled with the help of air quality monitoring project—Indian clean air programme, ARAI, Pune [16]. Onsite meteorological data was generated using Weather Research and Forecasting (WRF) model for hours of month May, which saved time and resources. National Centers for Environmental Prediction (NCEP) FNL (Final) Operational Global Analysis data were used as input of WRF whose resolution were at $1.0 \times 1.0$ degree grids, prepared operationally for every six hours. This product is from the Global Data Assimilation System (GDAS), which continuously collects observational data from the Global Telecommunications System (GTS), and other sources, for many analyses. These meteorological data from output of WRF model were prepared in spread sheet and was fed in AERMET with preprocessor of AERMOD. Later, AERMOD model was used for prediction of $\mathrm{NO}_{\mathrm{x}}$ and PM concentration from traffic emission for the six roads of Chembur.

\section{Results and Discussion}

In the present study, $\mathrm{NO}_{\mathrm{x}}$ and $\mathrm{PM}$ emission has been modelled for the month of May, 2011 to find out the dominant source in the study domain. May month is the pre-monsoon season and it is critical like December and has high concentration of pollutant for Mumbai city. Vehicular emission varies with time of the day i.e. morning peak, evening peak, off peak and lean peak. So, vehicular emission modelling has been done to see this effect. The model results were compared with observed value of concentration [17]. Here, modelling was carried out for all the sources of the region (given Table A1 in Appendix).

Figure 2 shows the wind rose of May 2011 generated by WRF which has been used in air quality modelling of vehicular sources for the study domain for six roads. The wind rose shows that maximum period of time wind is blowing from north-west corner. The maximum wind speed is $9 \mathrm{~m} / \mathrm{s}$ and minimum wind speed is $0.3 \mathrm{~m} / \mathrm{s}$. The

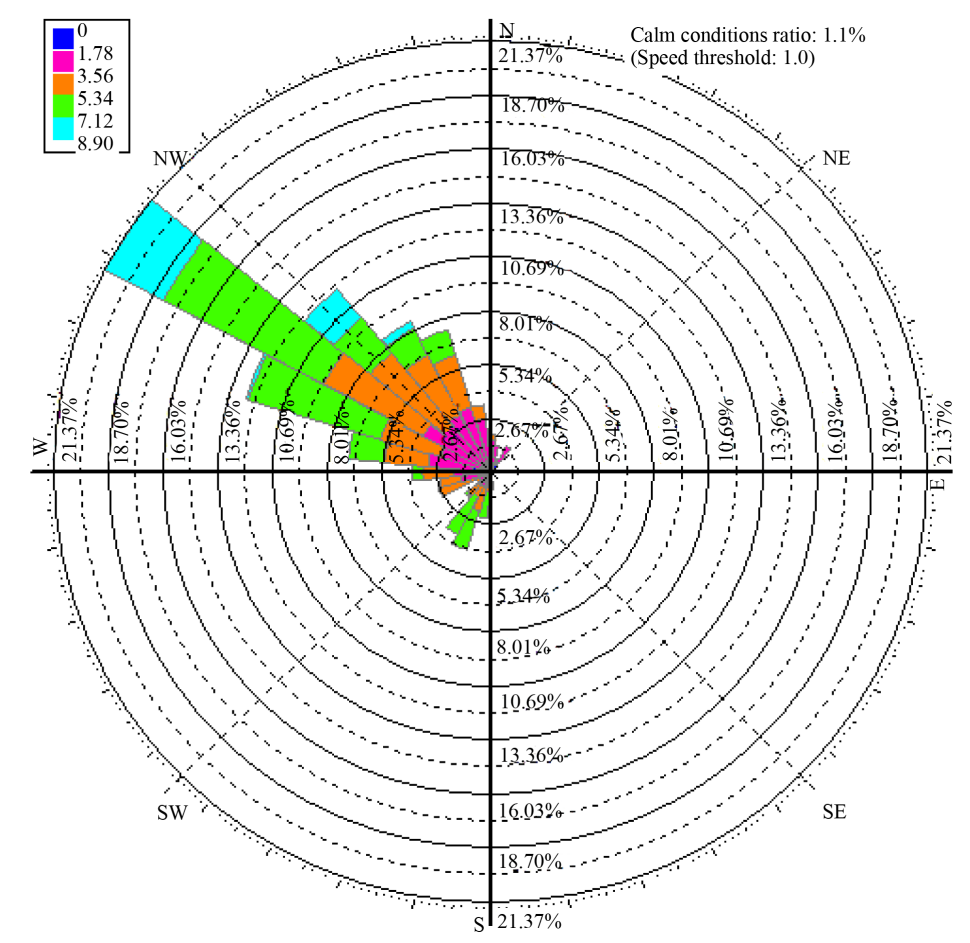

Figure 2. Wind rose of May 2011. 
calm condition was $1.1 \%$ of time where $1 \mathrm{~m} / \mathrm{s}$ was wind speed threshold. A very low frequency of wind is from south-west direction with wind speed around $5 \mathrm{~m} / \mathrm{s}$.

\section{1. $\mathrm{NO}_{\mathrm{x}}$ Concentration by Vehicles}

Figure 3 shows $\mathrm{NO}_{\mathrm{x}}$ concentration by vehicles in the study area. The north part of study area has high density of vehicles and is dominated by vehicular sources. Maximum concentration of $\mathrm{NO}_{\mathrm{x}}$ is $38 \mathrm{\mu g} / \mathrm{m}^{3}$ in Chedda Nagar. Around 15 to $25 \mu \mathrm{g} / \mathrm{m}^{3} \mathrm{NO}_{\mathrm{x}}$ concentrations are in Shramjivi Nagar and Jyothi Nagar which are in the north part of the study domain. In May, 2011, wind profile shows that maximum period of time, wind is blowing from north-west corner, so pollutant concentration is high in the north direction of study area and Chuna Bhati has lowest concentration as $10 \mu \mathrm{g} / \mathrm{m}^{3}$.

\subsection{PM Concentration by Vehicles}

Figure 4 shows contour plot of PM concentration from vehicles in the study area. The north part of study area is dominated by vehicular sources. Maximum concentration of PM is $36 \mu \mathrm{g} / \mathrm{m}^{3}$ in Chembur Naka and Chedda Nagar near Ghatkopar-Mankhurd Road. Shramjivi Nagar and Jyothi Nagar have almost 32 to $34 \mu \mathrm{g} / \mathrm{m}^{3}$ concentrations. In May 2011, wind profile shows that maximum period of time, wind is blowing from north-west corner so, pollutant concentration is being transported to north part of study area and Chuna Bhati has lowest concentration $31 \mu \mathrm{g} / \mathrm{m}^{3}$. In the modelling of PM emission $30 \mu \mathrm{g} / \mathrm{m}^{3}$ has been taken background concentration which includes resuspended particulate matter based on the work done earlier (Kumar, 2012).

\subsection{Comparison of AERMOD Results with Monitored Data}

Comparison of AERMOD output has been done with observed data of Brihanmumbai Municipal Corporation

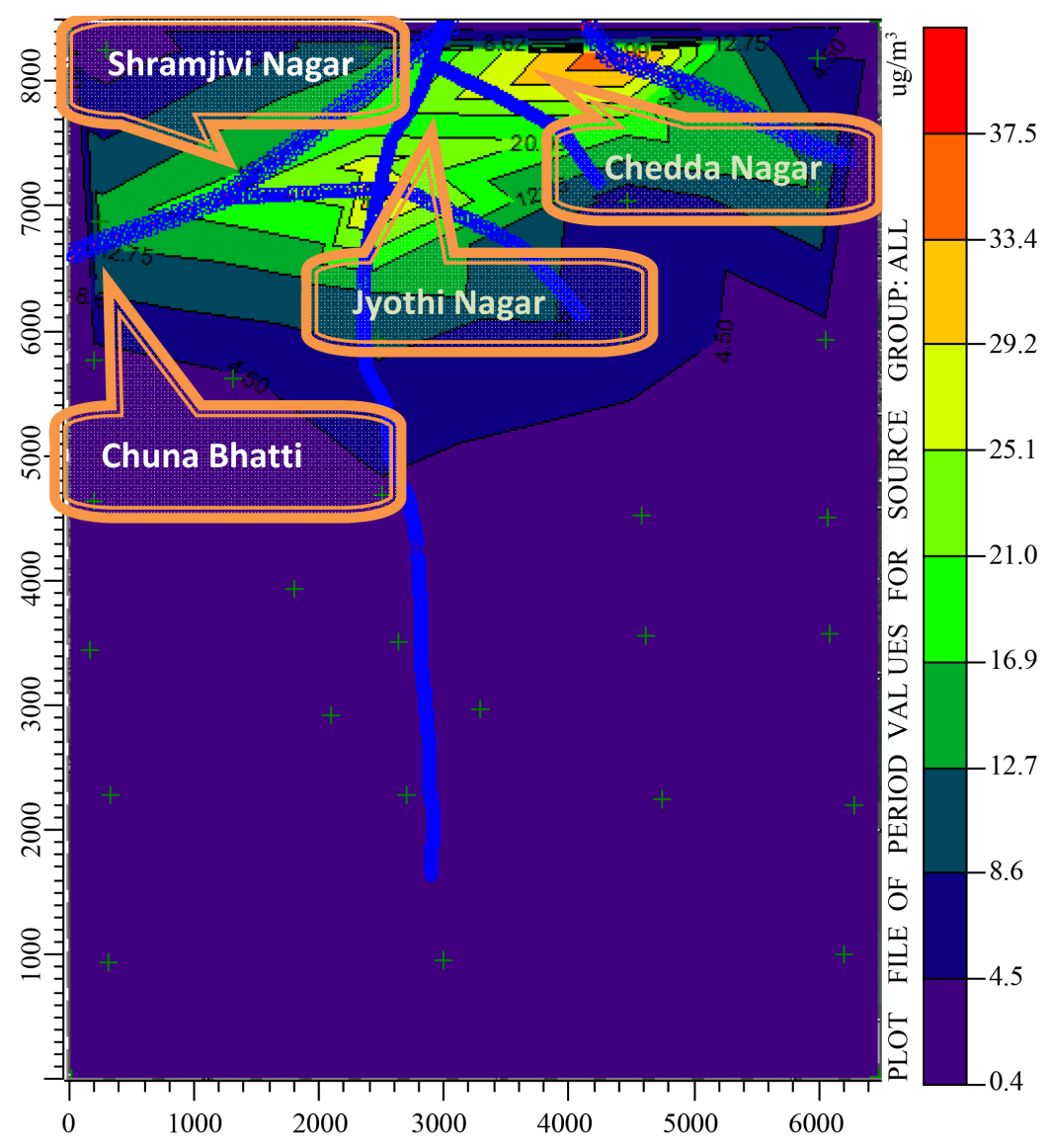

Figure $3 . \mathrm{NO}_{\mathrm{x}}$ concentration by vehicles in Chembur. 


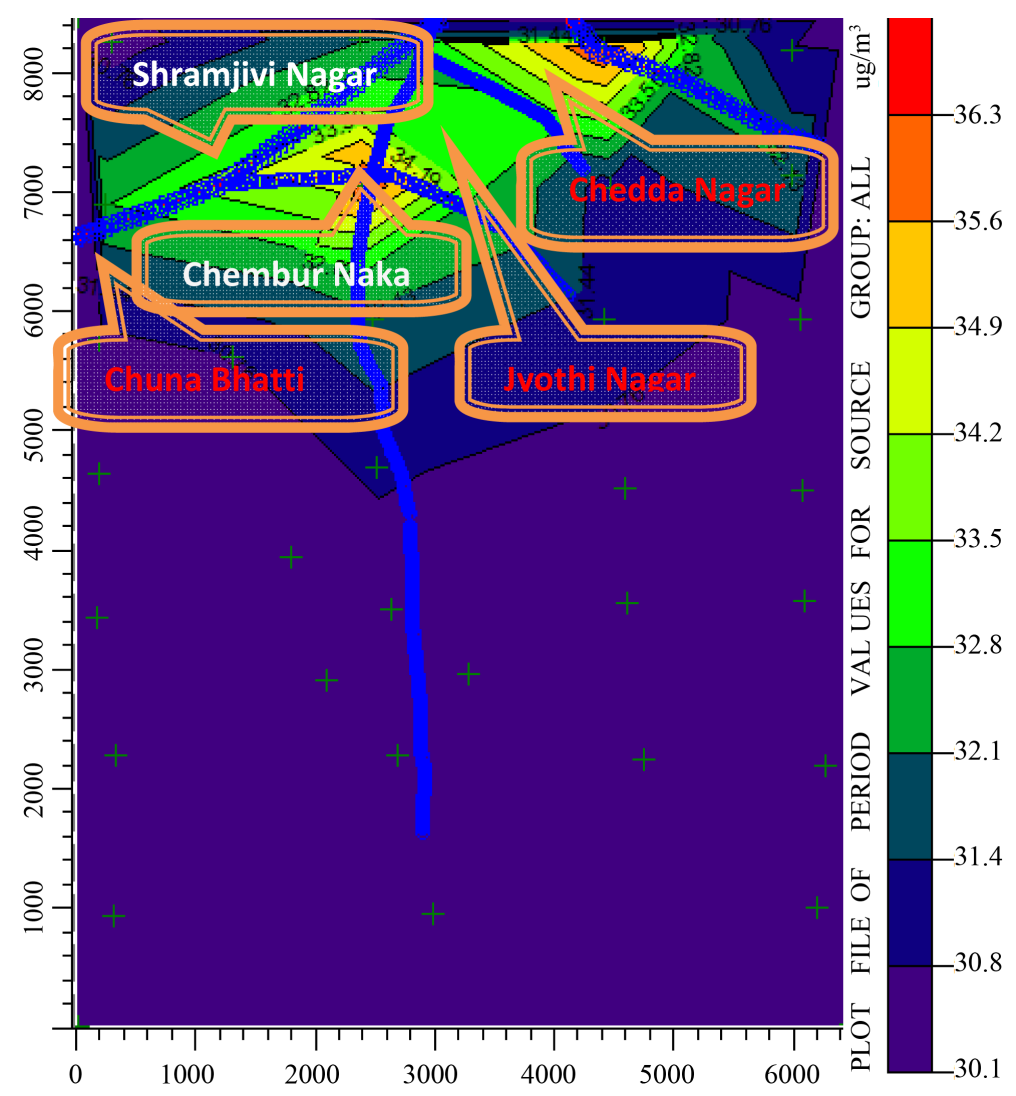

Figure 4. PM concentration by vehicles.

(BMC) at Maravali location (Near RCF). Here ambient monitoring is being done continuously for air quality parameters. The simulated concentration of $\mathrm{NO}_{\mathrm{x}}$ is $12 \mu \mathrm{g} / \mathrm{m}^{3}$ from vehicles while observed concentration by BMC was $34 \mu \mathrm{g} / \mathrm{m}^{3}$ which includes all the sources. The contribution of $\mathrm{NO}_{\mathrm{x}}$ concentration is $35 \%$ to ambient air quality. The simulated concentration of PM is $33 \mu \mathrm{g} / \mathrm{m}^{3}$ while observed concentration of PM is $335 \mu \mathrm{g} / \mathrm{m}^{3}$ by BMC at Maravali. This shows that around $10 \%$ contribution of PM is by vehicles to ambient air quality. PM emissions are mainly caused by background concentration and resuspended particulate matter, hence contribution by vehicles.

\section{Conclusion}

The aim of the study was to generate onsite meteorological profiles for using in vehicular pollution modelling of Chembur area. The advance WRF model was used successfully in this study. It generates onsite and real time meteorological data which is fed in AERMET pre-processor of dispersion model AERMOD. The integrated model was applied in May 2011 for all vehicular sources. The results show that contribution of $\mathrm{NO}_{\mathrm{x}}$ concentration in total $\mathrm{NO}_{\mathrm{x}}$ in ambient air is about 35\% from vehicles. Contribution of PM concentration is very low as emission from vehicles is low. The PM result is not in a good agreement with observed data because emission inventory is taken only for vehicles. In this study, WRF model has been used successfully for prediction of air quality. It shows that the use of WRF model can save considerable cost for processing the data as compared to collecting from meteorological station.

\section{References}

[1] Amundsen, A.H., Klæboe, R. and Fyhri, A. (2008) Annoyance from Vehicular Air Pollution: Exposure-Response Relationships for Norway. Atmospheric Environment, 42, 7679-7688. http://dx.doi.org/10.1016/j.atmosenv.2008.05.026

[2] Cheng, S., Lang, J., Zhou, Y., Han, L., Wang, G. and Chen, D. (2013) A New Monitoring-Simulation-Source Appor- 
tionment Approach for Investigating the Vehicular Emission Contribution to the PM2.5 Pollution in Beijing, China. Atmospheric Environment, 79, 308-316. http://dx.doi.org/10.1016/j.atmosenv.2013.06.043

[3] Fan, X., Lam, K.C. and Yu, Q. (2012) Differential Exposure of the Urban Population to Vehicular Air Pollution in Hong Kong. Science of the Total Environment, 426, 211-219. http://dx.doi.org/10.1016/j.scitotenv.2012.03.057

[4] Fenger, J. (2009) Air Pollution in the Last 50 Years-From Local to Global. Atmospheric Environment, 43, 13-22. http://dx.doi.org/10.1016/j.atmosenv.2008.09.061

[5] Nagendra, S.M.S. and Khare, M. (2002) Line Source Emission Modelling. Atmospheric Environment, 36, $2083-2098$. http://dx.doi.org/10.1016/S1352-2310(02)00177-2

[6] Neema, M.N. and Jahan, J. (2014) An Innovative Approach to Mitigate Vehicular Emission through Roadside Greeneries: A Case Study on Arterial Roads of Dhaka City. Journal of Data Analysis and Information Processing, 2, 32-39. http://dx.doi.org/10.4236/jdaip.2014.21005

[7] Province, H., Wang, L., Yang, J., Zhang, P., Zhao, X., Wei, Z., Zhang, F., Su, J. and Meng, C. (2013) A Review of Air Pollution and Control in Hebei Province. Journal of Data Analysis and Information Processing, 2, 47-55.

[8] Sharma, N., Chaudhry, K.K. and Rao, C.V.C. (2004) Vehicular Pollution Prediction Modelling: A Review of Highway Dispersion Models. Transport Review, 24, 409-435. http://dx.doi.org/10.1080/0144164042000196071

[9] Sivacoumar, R. and Thanasekaran, K. (1999) Line Source Model for Vehicular Pollution Prediction near Roadways and Model Evaluation through Statistical Analysis. Environmental Pollution, 104, 389-395. http://dx.doi.org/10.1016/S0269-7491(98)00190-0

[10] Benson P.E. (1979) CALINE-3, a Versatile Dispersion Model for Predicting Air Pollutant Levels near Highways and Arterial Streets. FHWA/CA/TL-79/23, California Department of Transportation, Sacraments.

[11] Petersen, W.B. (1980) Users Guide for HIWAY-2. Highway Air Pollution Model EPA-600/8-80-018.

[12] Chock, D.P. (1978) A Simple Line-Source Model for Dispersion near Roadways Atmospheric Environment, 12, 823829. http://dx.doi.org/10.1016/0004-6981(78)90019-7

[13] Luhar, A.K. and Patil, R.S. (1989) A General Finite Line Source Mode for Vehicular Pollution Prediction. Atmospheric Environment, 23, 555-562. http://dx.doi.org/10.1016/0004-6981(89)90004-8

[14] Noll, E.K., Miller, T.L. and Claggett, M. (1978) A Comparison of Three Highway Line Source Dispersion Models. Atmospheric Environment, 12, 1323-1329. http://dx.doi.org/10.1016/0004-6981(78)90072-0

[15] Csanady, G.T. (1972) Crosswinds Shear Effects on Atmospheric Diffusion. Atmospheric Environment, 6, $221-232$. http://dx.doi.org/10.1016/S0004-6981(72)80150-1

[16] Air Quality Monitoring Project-Indian Clean Air Programme (ICAP) (2008) Emission Factor Development for Indian Vehicles. ARAI, Pune.

[17] Kumar, A. (2012) Urban Air Quality Modelling. M.Sc. Thesis, Center for Environmental Science and Engineering, IIT Bombay, Mumbai.

\section{Appendix}

Table A1. Comparison of simulated concentration with ambient observed concentration.

\begin{tabular}{cccc}
\hline Pollutant & Location & Simulated Conc. $\left(\boldsymbol{\mu g} / \mathbf{m}^{\mathbf{3}}\right)$ & Observed Conc. $\left(\boldsymbol{\mu g} / \mathbf{m}^{\mathbf{3}}\right)$ \\
\hline NO $_{\mathbf{x}}$ & BPCL & 22.7 & 26.2 \\
& HPCL & 21.7 & 21.3 \\
\multirow{2}{*}{ PM } & BPCL & 49.6 & 52.9 \\
& HPCL & 50.3 & 88.2 \\
\hline
\end{tabular}

